\title{
A Nationwide Assessment of the Burden of Urinary Tract Infection among Renal Transplant Recipients
}

\author{
Benjamin J. Becerra, ${ }^{1,2}$ Monideepa B. Becerra, ${ }^{2,3}$ and Nasia Safdar ${ }^{2,4}$ \\ ${ }^{1}$ School of Public Health, Loma Linda University, Loma Linda, CA 92350, USA \\ ${ }^{2}$ William S. Middleton Memorial Veterans Hospital, Madison, WI 53705, USA \\ ${ }^{3}$ Department of Health Science and Human Ecology, California State University San Bernardino, \\ San Bernardino, CA 92407, USA \\ ${ }^{4}$ Department of Medicine, University of Wisconsin, Madison, WI 53706, USA
}

Correspondence should be addressed to Nasia Safdar; ns2@medicine.wisc.edu

Received 28 December 2014; Revised 12 February 2015; Accepted 15 February 2015

Academic Editor: Bernhard K. Krämer

Copyright (C) 2015 Benjamin J. Becerra et al. This is an open access article distributed under the Creative Commons Attribution License, which permits unrestricted use, distribution, and reproduction in any medium, provided the original work is properly cited.

\begin{abstract}
Objective. Evaluate the prevalence and outcomes of urinary tract infection (UTI) among renal transplant recipients. Methods. A secondary analysis of the Nationwide Inpatient Sample 2009-2011 was conducted. Survey-weighted multivariable regression analyses were used to examine the impact of UTI on transplant complications, total charges, and length of stay. Results. A total of 1,044 renal transplant recipients, representing a population estimate of 49,862, were included in the study. UTI was most common in transplant recipients with hypertension (53\%) and prevalence was noted to be 28.2 and 65.9 cases per 1,000 for men and women, respectively. UTI increased the likelihood of transplant complications (182\% for men, $169 \%$ for women). Total charges were $28 \%$ higher among men as compared to $22 \%$ among women with UTI. Such infection also increased the length of stay by $87 \%$ among men and $74 \%$ among women. Discussion. UTI in renal transplant recipients was associated with prolonged length of stay, total charges, and increased odds of transplant complications. Interventions to prevent UTI among such patients should be a priority area for future research and practice.
\end{abstract}

\section{Introduction}

Urinary tract infection (UTI) is the most common type of hospital-acquired infection (HAI) among renal transplant patients, surpassing viral infections, pneumonia, and surgical site infections $[1,2]$. Renal transplant recipients are more likely to develop UTI as compared to the general population. Studies within the last decade have reported prevalence of such infection ranging from $13 \%$ to nearly $80 \%$ among renal transplant patients [3-9]. The classic signs and symptoms of UTI such as fever, urinary urgency, or abdominal pain may be lacking or attenuated in renal transplant recipients, due to immunosuppression [10].

While various risk factors of UTI have been evaluated in the literature, with consistency noted across studies on the heightened risk associated with increased age and female gender $[4,7,8,11]$, few studies have assessed the impact of UTI on patient or hospital outcomes. Much of the literature has reported graft dysfunction [9], graft loss [5, 8], and mortality $[7,8,12]$, while other researchers noted no such findings [3]. To our knowledge, limited studies have evaluated the negative impact of UTI on both patient and health resource utilization among renal transplant recipients, especially using a nationally representative data source.

Such an evaluation is imperative, as the literature notes that while in nontransplant populations UTI may present with urgency, frequency, painful voiding, lower abdomen pain, and fever, symptoms may be lacking among transplant recipients, potentially due to the masking effect of immunosuppressive medications [10]. These results highlight the potential negative impact of UTI among other transplant patients, though limited studies have highlighted the burden 


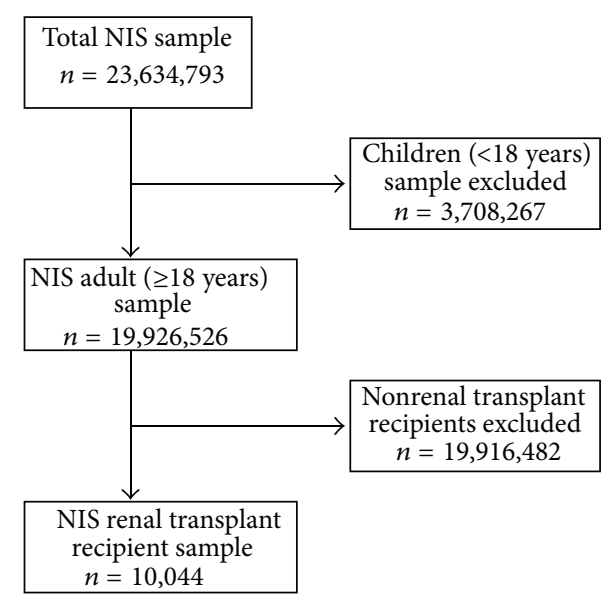

FIGURE 1: Sample selection procedure in study using Nationwide Inpatient Sample (NIS), 2009-2011.

among renal transplant patients. In this study, we addressed such a gap in the literature by utilizing a nationally representative survey and further evaluated the prevalence and impact of UTI on patient and hospital outcomes, including complications, length of stay, and total charges, among renal transplant recipients.

\section{Methods}

2.1. Data Source. We extracted data from 2009-2011 Nationwide Inpatient Sample (NIS), the largest publically available all-payer inpatient dataset in the United States. NIS is available yearly (since 1988) and includes data from all Agency for Healthcare Research and Quality (AHRQ) sponsored Healthcare Cost and Utilization Project (HCUP) participating states. Approximately, 8 million inpatient stays from 1,000 hospitals in the nation are included, reflective of a $20 \%$ sample of all nonfederal, short-term, general, and other specialty hospitals, except hospital units of institutions. Short-term rehabilitation (starting 1998), long-term acute care hospitals, psychiatric hospitals, and alcoholism/chemical dependency treatment facilities are excluded from NIS. Details of NIS data are described elsewhere [13].

In this study, our population was defined as those with a primary procedure code for renal transplant, resulting in a total of 10,044 discharges, representative of a population estimate of 49,862 recipients in the nation (average annual estimate $=16,621)$. Figure 1 displays the sample selection procedure. Missing values were excluded from statistical analyses.

2.2. Measures. The primary exposure variable of this study was UTI diagnosis among renal transplant recipients. We used the International Classification of Diseases, 9th Revision, Clinical Modification (ICD-9-CM) Procedure codes of $55.6,55.69$, or ICD-9-CM Diagnosis code of V42.0 to identify renal transplant recipients. UTI was identified with ICD-9CM code of 599.0.
The outcome variables were transplant complications, total charges, and length of stay. Transplant complications were defined as transplant failure or rejection (ICD-9-CM 996.81). Total charges and length of stay were both edited by AHRQ for uniformity between states. To account for inflation, we adjusted total charges to 2009 USD using the Gross Domestic Product (GDP) deflator from the United States Department of Commerce, Bureau of Economic Analysis [14].

Control variables comprised of both patient and hospital characteristics, in addition to survey year (2009, 2010, and 2011). Patient characteristics included donor type (live, deceased), age (18-34 years, 35-49 years, 50-64 years, 65 years or more), gender (men, women), race/ethnicity (White, Black, Hispanic, and others), median household income quartiles by patient ZIP code (\$1-\$38999, \$39000-\$47999, $\$ 48000-\$ 62999$, \$63000 or more), primary payer type (Medicare, Medicaid, private including $\mathrm{HMO}$, and others), and Charlson-Deyo index to take into account potential effect of other comorbid conditions.

The Charlson-Deyo index is a validated comorbidity measure for administrative data [15-17]. The index is comprised of 17 comorbidities, including myocardial infarction, congestive heart failure, peripheral vascular disease, cerebrovascular disease, dementia, chronic pulmonary disease, rheumatic disease, peptic ulcer disease, mild liver disease, diabetes with and without chronic complications, hemiplegia or paraplegia, renal disease, any malignancy (including lymphoma and leukemia, except malignant neoplasm of skin), moderate or severe liver disease, metastatic solid tumor, and human immunodeficiency virus/acquired immunodeficiency syndrome.

Hospital characteristics included bed size tertiles (small, medium, and large), hospital control or ownership (government nonfederal, private nonprofit, and private investor own), teaching status (teaching and nonteaching), and geographic location (Northeast, Midwest, South, and West).

2.3. Statistical Analyses. We conducted survey-weighted descriptive statistics to evaluate the prevalence of UTI among renal transplant recipients, in addition to the distribution of both patient and hospital characteristics in the entire sample, by gender. In order to assess the impact of UTI on complications of transplant among renal transplant recipients, we conducted chi-square tests followed by survey-weighted binary logistic regression analyses for both men and women. We used Wilcoxon rank sum to assess differences in total charges and length of stay among renal transplant recipients with UTI, as compared to those without. Finally, we conducted survey-weighted linear and negative binomial regressions to assess the impact of UTI on total charges and length of stay, respectively. In addition, log-transformation was employed for total charges due to nonnormality of such data.

Given that older adults are more likely to experience worse health and hospital outcomes due to a greater frequency of comorbid conditions [18-20], we conducted a sensitivity analysis to evaluate if the negative impact of UTI among renal transplant recipients was present among adults less than 65 years of age. 
We used SAS 9.4 (SAS Institute, Inc., Cary, NC) for all statistical analyses except for negative binomial regression, for which we used STATA 12 package (Stata Corp LP, College Station, TX). Survey weights were applied in all statistical analyses, unless otherwise stated, in addition to design-based $F$ values for variance estimation. To reduce rate of type I error due to multiple testing, we employed a Bonferroni familywise correction and $P<0.003$ was used to denote significance for all statistical analyses. The STROBE checklist for observational studies was followed for reporting results.

\section{Results}

As summarized in Table 1, we found a prevalence of 28.2 and 65.9 cases of UTI per 1,000 for men and women, respectively, in the study population of renal transplant recipients. The majority of transplant patients received kidneys from deceased donors (60\% men, 63\% women), were aged 5064 years (39\% men, 38\% women), were White ( $49 \%$ men, $47 \%$ women), had Medicare (59\% men, $60 \%$ women), and were hospitalized in a teaching hospital (95\% men, 96\% women). While income and comorbidity distribution were nearly equal in all categories for both genders, the highest percent of renal transplants occurred in the Southern states (37\% men, 38\% women).

Rate of complications was higher for men who were renal transplant recipients with UTI as compared to those without ( $42 \%$ versus $19 \%, P<0.0001)$. A similar trend was noted among women with UTI as compared to those without (38\% versus $18 \%, P<0.0001)$. Results of survey-weighted multivariable logistic regression analysis showed that renal transplant recipients with UTI were nearly three times more likely to have complications of transplant (adjusted odds ratio $(\mathrm{aOR})$ men $=2.8 ; \mathrm{aOR}$ women $=2.6)$, as compared to those without UTI (Table 2).

UTI was also associated with increased total charges for both men ( $\$ 549,659$ versus $\$ 335,711, P<0.0001)$ and women (\$509,714 versus $\$ 335,140, P<0.0001)$. Results of surveyweighted multiple linear regression analyses (Table 3 ) showed that UTI was associated with significantly higher total charges among both men (24\%) and women (22\%).

Renal transplant recipients with UTI had increased length of stay as compared to those without such infection (10 days versus 6 days for men, $P<0.0001$; 9 days versus 6 days for women, $P<0.0001)$. Negative binomial regression results demonstrated that UTI was associated with increases in length of stay for men (adjusted incidence rate ratio (aIRR) = $1.9)$ and women $(\mathrm{aIRR}=1.7)$ renal transplant recipients, respectively (Table 4 ).

We also found gender differences on the burden of UTI among such transplant recipients. For example, men were $182 \%$ more likely while women were $160 \%$ more likely to have complications upon UTI (Table 2). Similarly, total charges were $28 \%$ higher among men as compared to $22 \%$ among women with UTI (Table 3). Finally, UTI increased the likelihood of length of stay among men by $87 \%$ as compared to $74 \%$ among women (Table 4 ).

Several other characteristics were associated with increased complications, charges, or length of stay among
TABLE 1: Characteristics of study population ( $n$, weighted \%), NIS 2009-2011 ( $n=10,044 ; N=49,862)$.

\begin{tabular}{|c|c|c|}
\hline & Men & Women \\
\hline Urinary tract infection & $173(2.82)$ & $262(6.59)$ \\
\hline \multicolumn{3}{|l|}{ Donor type } \\
\hline Deceased & $3,650(60.19)$ & $2,467(62.53)$ \\
\hline Live & $2,236(36.44)$ & $1,351(34.11)$ \\
\hline Missing & $204(3.37)$ & $132(3.35)$ \\
\hline \multicolumn{3}{|l|}{ Age (years) } \\
\hline $18-34$ & $820(13.38)$ & $640(16.23)$ \\
\hline $35-49$ & $1,829(29.93)$ & $1,167(29.42)$ \\
\hline $50-64$ & $2,390(39.26)$ & $1,515(38.37)$ \\
\hline 65 or more & $1,051(17.42)$ & $628(15.98)$ \\
\hline \multicolumn{3}{|l|}{ Race/ethnicity } \\
\hline White & $2,999(49.32)$ & $1,864(47.26)$ \\
\hline Black & $1,313(21.59)$ & $936(23.59)$ \\
\hline Hispanic & $887(14.64)$ & $562(14.31)$ \\
\hline Others & $455(7.51)$ & $317(8.20)$ \\
\hline Missing & $436(6.93)$ & $271(6.64)$ \\
\hline \multicolumn{3}{|l|}{ Charlson-Deyo index } \\
\hline Two or less & 2,993 (49.09) & $1,913(48.63)$ \\
\hline Three or more & $3,097(50.91)$ & $2,037(51.37)$ \\
\hline \multicolumn{3}{|l|}{ Neighborhood income } \\
\hline$\$ 1-\$ 38,999$ & $1,595(26.04)$ & $1,132(28.50)$ \\
\hline$\$ 39,000-\$ 47,999$ & $1,475(24.16)$ & $939(23.81)$ \\
\hline$\$ 48,000-\$ 62,999$ & $1,527(25.25)$ & $952(24.16)$ \\
\hline$\$ 63,000$ or more & $1,351(22.22)$ & $841(21.34)$ \\
\hline Missing & $142(2.34)$ & $86(2.18)$ \\
\hline \multicolumn{3}{|l|}{ Payer type } \\
\hline Private including $\mathrm{HMO}$ & $2,021(33.03)$ & $1,253(31.66)$ \\
\hline Medicare & $3,589(59.06)$ & $2,370(60.02)$ \\
\hline Medicaid & $201(3.36)$ & $154(3.96)$ \\
\hline Others & $215(3.46)$ & $129(3.19)$ \\
\hline Missing & $64(1.08)$ & $44(1.16)$ \\
\hline \multicolumn{3}{|l|}{ Teaching status } \\
\hline Nonteaching & $172(2.65)$ & $80(1.94)$ \\
\hline Teaching & $5,801(95.46)$ & $3,799(96.30)$ \\
\hline Missing & $117(1.89)$ & $71(1.76)$ \\
\hline \multicolumn{3}{|l|}{ Geographic location } \\
\hline Northeast & 1,073 (17.99) & $621(15.97)$ \\
\hline Midwest & $1,512(23.86)$ & $1,000(24.35)$ \\
\hline South & $2,250(36.54)$ & $1,508(37.75)$ \\
\hline West & 1,255 (21.61) & $821(21.93)$ \\
\hline \multicolumn{3}{|l|}{ Year } \\
\hline 2009 & $2,201(35.81)$ & $1,411(35.48)$ \\
\hline 2010 & $1,944(33.76)$ & $1,245(33.37)$ \\
\hline 2011 & $1,945(30.43)$ & $1,294(31.16)$ \\
\hline
\end{tabular}

such transplant patients. Organ donation from deceased donor substantially increased the likelihood of transplant complications $(\mathrm{aOR}$ men $=2.3$; $\mathrm{aOR}$ women $=1.9)$, percent increase in total charges $($ men $=17.9$; women $=18.9)$, and length of stay (aIRR $=1.3$ for men and women). Having Medicare was related to increased odds of transplant complications $(\mathrm{aOR}$ men $=1.3$; $\mathrm{aOR}$ women $=1.5)$ and length of stay ( $\operatorname{aIRR}=1.1$ for men and women). Other patient and hospital characteristics associated with increased total 
TABLE 2: Multivariable logistic regression odds ratio (and 95\% CI) for complications of transplant among renal transplant recipients, NIS 2009-2011.

\begin{tabular}{|c|c|c|c|c|}
\hline & \multicolumn{2}{|c|}{ Men } & \multicolumn{2}{|c|}{ Women } \\
\hline & OR $(95 \% \mathrm{CI})$ & $P$ value & OR $(95 \% \mathrm{CI})$ & $P$ value \\
\hline UTI versus no UTI & $2.82(1.90,4.18)$ & $<0.001^{*}$ & $2.60(1.89,3.58)$ & $<0.001^{*}$ \\
\hline Deceased donor versus live & $2.29(1.92,2.73)$ & $<0.001^{*}$ & $1.87(1.45,2.41)$ & $<0.001^{*}$ \\
\hline \multicolumn{5}{|l|}{ Age (Ref. = $18-34$ years $)$} \\
\hline $35-49$ years & $0.97(0.81,1.16)$ & 0.71 & $0.99(0.73,1.35)$ & 0.94 \\
\hline $50-64$ years & $0.83(0.68,1.02)$ & 0.08 & $0.84(0.61,1.15)$ & 0.27 \\
\hline 65 years or more & $0.80(0.59,1.09)$ & 0.15 & $0.60(0.42,0.87)$ & 0.01 \\
\hline \multicolumn{5}{|l|}{ Race/ethnicity (Ref. = White) } \\
\hline Black & $0.89(0.74,1.07)$ & 0.20 & $0.86(0.70,1.06)$ & 0.16 \\
\hline Hispanic & $0.97(0.77,1.22)$ & 0.80 & $0.90(0.69,1.17)$ & 0.42 \\
\hline Others & $0.84(0.60,1.17)$ & 0.30 & $0.70(0.49,1.00)$ & 0.05 \\
\hline $\begin{array}{l}\text { Charlson-Deyo index } 3 \text { or more versus } \\
2 \text { or less }\end{array}$ & $0.90(0.78,1.04)$ & 0.15 & $0.83(0.68,1.02)$ & 0.07 \\
\hline \multicolumn{5}{|l|}{$\begin{array}{l}\text { Neighborhood income (Ref. }= \\
\$ 1-\$ 38,999)\end{array}$} \\
\hline$\$ 39,000-\$ 47,999$ & $1.14(0.94,1.37)$ & 0.18 & $1.20(0.92,1.55)$ & 0.18 \\
\hline$\$ 48,000-\$ 62,999$ & $1.01(0.80,1.28)$ & 0.93 & $1.41(1.11,1.80)$ & 0.005 \\
\hline$\$ 63,000$ or more & $1.20(0.95,1.51)$ & 0.13 & $1.36(1.05,1.75)$ & 0.02 \\
\hline \multicolumn{5}{|l|}{$\begin{array}{l}\text { Payer type }(\text { Ref. }=\text { private including } \\
\text { HMO })\end{array}$} \\
\hline Medicare & $1.31(1.11,1.55)$ & $0.001^{*}$ & $1.51(1.27,1.81)$ & $<0.001^{*}$ \\
\hline Medicaid & $1.38(0.96,1.98)$ & 0.09 & $1.21(0.75,1.97)$ & 0.43 \\
\hline Others & $0.43(0.19,0.99)$ & 0.05 & $1.23(0.60,2.51)$ & 0.57 \\
\hline Teaching versus nonteaching & $1.21(0.87,1.68)$ & 0.25 & $1.40(0.57,3.47)$ & 0.46 \\
\hline \multicolumn{5}{|l|}{ Geographic location $($ Ref. $=$ Northeast $)$} \\
\hline Midwest & $0.84(0.48,1.48)$ & 0.55 & $0.71(0.49,1.04)$ & 0.08 \\
\hline South & $0.73(0.45,1.17)$ & 0.19 & $0.59(0.41,0.85)$ & 0.004 \\
\hline West & $0.97(0.62,1.51)$ & 0.88 & $0.59(0.39,0.90)$ & 0.01 \\
\hline \multicolumn{5}{|l|}{ Year $($ Ref. $=2009)$} \\
\hline 2010 & $0.89(0.63,1.25)$ & 0.50 & $1.11(0.85,1.46)$ & 0.44 \\
\hline 2011 & $1.04(0.72,1.50)$ & 0.85 & $1.17(0.87,1.58)$ & 0.30 \\
\hline
\end{tabular}

*Bonferroni $P<0.003$.

Ref. $=$ reference category, $\mathrm{UTI}=$ urinary tract infection, $\mathrm{OR}=$ odds ratio, and $\mathrm{CI}=$ confidence interval.

charges were having three or more comorbidities, teaching status of hospital, and increasing calendar year. Increased length of stay was also significantly associated with three or more comorbidities and having Medicaid (for men only).

Sensitivity analyses further demonstrated that the negative impact of UTI remained significant among adult renal transplant recipients aged 64 years or less (Table 5). UTI was significantly associated with transplant complications among both men $(\mathrm{aOR}=3.45)$ and women $(\mathrm{aOR}=2.68)$. Similarly, men and women renal transplant patients with UTI had nearly $30 \%$ and $22 \%$ higher total charges, as compared to those with no such infection. We also found that, compared to those without UTI, length of stay was $74 \%$ and $76 \%$ higher among men and women renal transplant recipients, respectively, with UTI.

\section{Discussion}

Using a large nationally representative sample, we found that UTI remains a significant complication among renal transplant patients and is associated with considerable negative outcomes in this patient population. We found that risks of transplant complications (transplant failure or rejection) were significantly higher for both men and women renal transplant recipients with UTI, as were increased rates of health resource utilization (total charges and length of stay).

Previous studies of UTI in renal transplant recipients have shown that both early and late UTI may have serious adverse consequences in this population. While some of these studies have noted increased hospital days and costs related to catheter-associated UTI $[21,22]$, few to date have evaluated 
TABLE 3: Multiple linear regression for percent change in total charges in dollars (and 95\% CI) among renal transplant recipients, NIS 20092011.

\begin{tabular}{|c|c|c|c|c|}
\hline & \multicolumn{2}{|l|}{ Men } & \multicolumn{2}{|l|}{ Women } \\
\hline & Percent change (95\% CI) & $P$ value & Percent change (95\% CI) & $P$ value \\
\hline UTI versus no UTI & $28.43(17.49,39.38)$ & $<0.001^{*}$ & $22.07(14.38,29.76)$ & $<0.001^{*}$ \\
\hline Deceased donor versus live & $17.89(12.46,23.32)$ & $<0.001^{*}$ & $18.75(12.24,25.26)$ & $<0.001^{*}$ \\
\hline \multicolumn{5}{|l|}{ Age (Ref. = 18-34 years) } \\
\hline $35-49$ years & $-1.77(-6.26,2.72)$ & 0.44 & $-2.08(-6.57,2.41)$ & 0.36 \\
\hline $50-64$ years & $-5.89(-10.53,-1.26)$ & 0.01 & $-5.31(-9.79,-0.83)$ & 0.02 \\
\hline 65 years or more & $-4.70(-10.01,0.61)$ & 0.08 & $-5.95(-12.00,0.09)$ & 0.05 \\
\hline \multicolumn{5}{|l|}{ Race/ethnicity (Ref. = White) } \\
\hline Black & $8.50(1.52,15.49)$ & 0.02 & $5.26(-2.20,12.73)$ & 0.17 \\
\hline Hispanic & $2.51(-6.78,11.79)$ & 0.60 & $5.41(-4.83,15.65)$ & 0.30 \\
\hline Others & $-4.68(-13.16,3.80)$ & 0.28 & $-5.79(-13.56,1.97)$ & 0.14 \\
\hline $\begin{array}{l}\text { Charlson-Deyo index } 3 \text { or more versus } \\
2 \text { or less }\end{array}$ & $8.43(5.72,11.13)$ & $<0.001^{*}$ & $10.67(7.44,13.90)$ & $<0.001^{*}$ \\
\hline \multicolumn{5}{|l|}{$\begin{array}{l}\text { Neighborhood income (Ref. = } \\
\$ 1-\$ 38,999)\end{array}$} \\
\hline$\$ 39,000-\$ 47,999$ & $-0.47(-5.01,4.08)$ & 0.84 & $-0.45(-5.62,4.72)$ & 0.86 \\
\hline$\$ 48,000-\$ 62,999$ & $-0.99(-6.45,4.47)$ & 0.72 & $1.91(-4.57,8.39)$ & 0.56 \\
\hline$\$ 63,000$ or more & $-0.59(-8.74,7.57)$ & 0.89 & $1.22(-9.23,11.68)$ & 0.82 \\
\hline \multicolumn{5}{|l|}{$\begin{array}{l}\text { Payer type }(\text { Ref. = private including } \\
\text { HMO) }\end{array}$} \\
\hline Medicare & $6.05(1.75,10.34)$ & 0.01 & $7.83(2.59,13.07)$ & 0.003 \\
\hline Medicaid & $17.91(4.28,31.54)$ & 0.01 & $14.00(0.17,27.83)$ & 0.05 \\
\hline Others & $7.19(-7.68,22.07)$ & 0.34 & $3.39(-15.40,22.18)$ & 0.72 \\
\hline Teaching versus nonteaching & $-43.74(-61.71,-25.77)$ & $<0.001^{*}$ & $-43.99(-58.62,-29.35)$ & $<0.001^{*}$ \\
\hline \multicolumn{5}{|l|}{ Geographic location (Ref. = Northeast) } \\
\hline Midwest & $15.96(-5.46,37.37)$ & 0.14 & $13.85(-6.69,34.40)$ & 0.19 \\
\hline South & $-8.95(-30.53,12.63)$ & 0.42 & $-9.85(-30.03,10.32)$ & 0.34 \\
\hline West & $10.93(-16.23,38.08)$ & 0.43 & $11.17(-13.91,36.25)$ & 0.38 \\
\hline \multicolumn{5}{|l|}{ Year $($ Ref. = 2009) } \\
\hline 2010 & $94.38(80.54,108.23)$ & $<0.001^{*}$ & $94.51(81.51,107.50)$ & $<0.001^{*}$ \\
\hline 2011 & $159.01(144.82,173.20)$ & $<0.001^{*}$ & $157.94(144.51,171.36)$ & $<0.001^{*}$ \\
\hline
\end{tabular}

* Bonferroni $P<0.003$.

Ref. $=$ reference category, UTI = urinary tract infection, and CI = confidence interval.

complications and health resource utilization related to UTI among renal transplant recipients. For example, Abbott and colleagues undertook a retrospective cohort study of 28,942 Medicare primary renal transplant recipients in the United States Renal Data System database from 1996 through 2000, assessing Medicare claims for UTI occurring later than 6 months after transplantation based on ICD-9 codes, and found that the cumulative incidence of UTI during the first 6 months after renal transplantation was 17\% (equivalent for both men and women) and at 3 years was $60 \%$ for women and $47 \%$ for men $(P<0.001$ in Cox regression analysis). Late UTI was significantly associated with an increased risk of subsequent death and graft loss. Our study extends the literature in this area by using the largest national inpatient sample which is not limited to Medicare claims [8].

In a retrospective analysis on 500 adult renal transplant recipients at two transplant centers in the United States, Chuang et al. [7] found that, within an average follow-up period of 42 months, approximately $43 \%$ of the transplant recipients developed UTI. While UTI did not significantly impact graft loss, it greatly increased mortality among such patients. In our study, we noted a similar negative impact on transplant complications among kidney recipients with UTI, though our results expanded beyond two national facilities and included a nationally representative sample.

In a study utilizing the United States Renal Data System database, Dhamidharka et al. [23] analyzed 1996-2000 Medicare claims to evaluate the impact of UTI 36 months after kidney transplant among 870 children. The authors found that early UTI (less than 6 months after transplant) was significantly ( $P=0.007$ upon multivariable Cox regression) associated with higher adjusted hazard ratio of graft loss, and late UTI was not associated with such outcome. The researchers further noted no significant association between UTI (early or late) and mortality. The results from our study on transplant complications, length of stay, and total charges demonstrate that potential postoperative UTI could not only have significant impact patient outcomes, but also increase health resource utilization and further burden the healthcare system. Such results, thus, highlight the need for monitoring UTI among renal transplant recipients to ensure positive outcomes. 
TABLE 4: Multivariable negative binomial incidence rate ratio (and 95\% CI) for length of stay among renal transplant recipients, NIS 20092011.

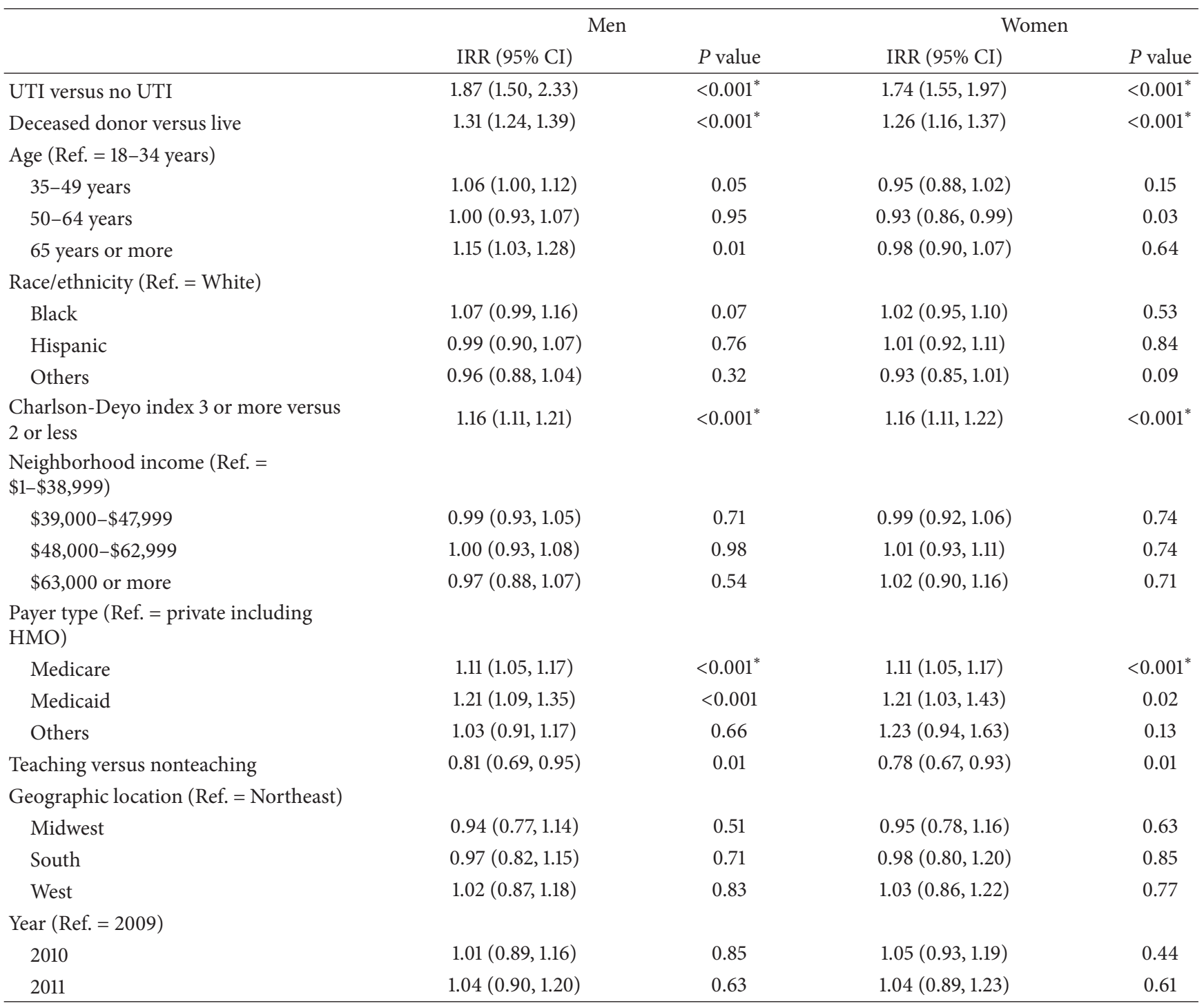

* Bonferroni $P<0.003$.

Ref. $=$ reference category, UTI $=$ urinary tract infection, $\mathrm{IRR}=$ incidence rate ratio, and $\mathrm{CI}=$ confidence interval.

TABLE 5: Multivariable regression analyses of sensitivity analysis (excluding 65 years or older) on impact of urinary tract infection among renal transplant recipients, NIS 2009-2011 ${ }^{\mathrm{a}}$.

\begin{tabular}{lccc}
\hline & Transplant complications & Total charges & Length of stay \\
& OR $(95 \%$ CI $)$ & Percent change (95\% CI) & $1.74(1.51,1.99)^{*}$ \\
Men & $3.45(2.62,5.26)^{*}$ & $29.51(18.32,40.70)^{*}$ & $1.76(1.56,1.97)^{*}$ \\
Women & $2.68(1.92,3.73)^{*}$ & $21.69(12.67,30.70)^{*}$ & IRR (95\% CI) \\
\hline
\end{tabular}

*Bonferroni $P<0.003$.

${ }^{a}$ Model adjusted for age, donor type, race/ethnicity, Charlson-Deyo index, neighborhood income, payer type, teaching status, geographic location of hospital, and year.

$\mathrm{OR}=$ odds ratio, $\mathrm{CI}=$ confidence interval, and $\mathrm{IRR}=$ incidence rate ratio.

Other researchers evaluating the complications of UTI on various patient populations have further reported the negative impacts. For example, Kang et al. [24] noted that, among colorectal cancer surgery patients, UTI was significantly associated with increased length of stay and hospital charges, as compared to those without UTI. Similarly, UTI has been associated with increased length of stay and hospital costs in general and major elective surgery patients $[21,25$, 26]. Cumulatively, the current empirical evidence notes a negative effect of UTI after surgery and/or transplantation. 
Our results further add to the limited body of literature on the complications and health resource utilization associated with UTI among adult renal transplant recipients.

In addition, we found gender differences in the adverse outcomes of UTI, with men reporting higher rates of complications, higher charges, and length of stay; and reasons for these differences should be explored in future studies. Several other factors, such as deceased donor, increased age, Medicare, and presence of several comorbidities, were significantly associated with negative outcomes in renal transplant recipients. Such results are consistent with previous studies that have shown increased risk of complications or mortality to be associated with use of deceased donor, increased age, or presence of other comorbidities among other patients [23, 27-29]. Given the relation to increased age and such outcomes, the association with Medicare was expected. Increased length of stay among men renal transplant recipients with Medicaid, however, highlights the excess burden among low-income men as Medicaid is intended primarily for individuals of low socioeconomic status.

The results of our study should be interpreted in the context of some limitations. The unit of analysis in NIS is discharge and thus evaluation of repeat patients and individuallevel variables could not be assessed. Our goal, however, in this study was to evaluate the burden of UTI among renal transplant hospitalizations, and such NIS provides an ideal data for such evaluation, though further studies on patientlevel data are warranted. In addition, the role of other patientlevel determinants, such as health literacy, education, and past experience in healthcare system, could not be evaluated. We also did not have data on the microbiology of UTI or treatment variables such as antibiotic use.

Our study also has a number of strengths. The use of a nationally representative sample ensures better variance estimations and thus results are generalizable to the United States population. Moreover, NIS includes a variety of payers including public and private and those who are uninsured, a significant strength as compared to other databases such as Medicare claims [30]. Our study of the NIS database highlights the prevalence and major negative consequences of UTI among renal transplant recipients. Given such outcomes, research to identify efficacious strategies to prevent UTI in kidney transplant recipients is needed.

\section{Conflict of Interests}

The authors declare no conflict of interests.

\section{Acknowledgment}

Dr. Nasia Safdar is supported by a VA MERIT award.

\section{References}

[1] S. R. P. E. Dantas, R. H. Kuboyama, M. Mazzali, and M. L. Moretti, "Nosocomial infections in renal transplant patients: risk factors and treatment implications associated with urinary tract and surgical site infections," Journal of Hospital Infection, vol. 63 , no. 2, pp. 117-123, 2006.
[2] G. J. Alangaden, R. Thyagarajan, S. A. Gruber et al., "Infectious complications after kidney transplantation: current epidemiology and associated risk factors," Clinical Transplantation, vol. 20, no. 4, pp. 401-409, 2006.

[3] N. S. Kamath, G. T. John, N. Neelakantan, M. G. Kirubakaran, and C. K. Jacob, "Acute graft pyelonephritis following renal transplantation," Transplant Infectious Disease, vol. 8, no. 3, pp. 140-147, 2006.

[4] G. Pellé, S. Vimont, P. P. Levy et al., "Acute pyelonephritis represents a risk factor impairing long-term kidney graft function," American Journal of Transplantation, vol. 7, no. 4, pp. 899-907, 2007.

[5] K. O. Memikoğlu, K. Keven, Ş. Şengül, Z. Soypaçaci, Ş. Ertürk, and B. Erbay, "Urinary tract infections following renal transplantation: a single-center experience," Transplantation Proceedings, vol. 39, no. 10, pp. 3131-3134, 2007.

[6] J. Gołębiewska, A. Dębska-Ślizień, J. Komarnicka, A. Samet, and B. Rutkowski, "Urinary tract infections in renal transplant recipients," Transplantation Proceedings, vol. 43, no. 8, pp. 29852990, 2011.

[7] P. Chuang, C. R. Parikh, and A. Langone, "Urinary tract infections after renal transplantation: a retrospective review at two US transplant centers," Clinical Transplantation, vol. 19, no. 2, pp. 230-235, 2005.

[8] K. C. Abbott, S. J. Swanson, E. R. Richter et al., "Late urinary tract infection after renal transplantation in the United States," American Journal of Kidney Diseases, vol. 44, no. 2, pp. 353-362, 2004.

[9] T. Iqbal, R. Naqvi, and S. F. Akhter, "Frequency of urinary tract infection in renal transplant recipients and effect on graft function," Journal of the Pakistan Medical Association, vol. 60, no. 10, pp. 826-829, 2010.

[10] M. Giessing, "Urinary tract infection in renal transplantation," Arab Journal of Urology, vol. 10, no. 2, pp. 162-168, 2012.

[11] R. Yacoub and N. Akl, "Urinary tract infections and asymptomatic bacteriuria in renal transplant recipients," Journal of Global Infectious Diseases, vol. 3, no. 4, pp. 383-389, 2011.

[12] S. Schmaldienst, E. Dittrich, and W. H. Hörl, "Urinary tract infections after renal transplantation," Current Opinion in Urology, vol. 12, no. 2, pp. 125-130, 2002.

[13] Agency for Healthcare Research and Quality, Introduction to the HCUP Nationwide Inpatient Sample (NIS), Agency for Healthcare Research and Quality, 2013, http://www.hcupus.ahrq.gov/db/nation/nis/NIS_Introduction_2011.pdf.

[14] US Department of Commerce/Bureau of Economic Analysis, "Bureau of Economic Analysis," 2014, http://www.bea.gov/iTable $/$ iTable.cfm?reqid $=9 \&$ step $=3 \&$ isuri $=1 \& 904=2009 \& 903=4 \&$ $906=\mathrm{q} \& 905=2014 \& 910=x \& 911=0 \#$ reqid $=9 \&$ step $=3 \&$ isuri $=1 \&$ 904=2009\&903=4\&906=q\&905=2014\&910=x\&911=0.

[15] M. E. Charlson, P. Pompei, K. L. Ales, and C. R. MacKenzie, "A new method of classifying prognostic comorbidity in longitudinal studies: development and validation," Journal of Chronic Diseases, vol. 40, no. 5, pp. 373-383, 1987.

[16] R. A. Deyo, D. C. Cherkin, and M. A. Ciol, "Adapting a clinical comorbidity index for use with ICD-9-CM administrative databases," Journal of Clinical Epidemiology, vol. 45, no. 6, pp. 613-619, 1992.

[17] H. Quan, V. Sundararajan, P. Halfon et al., "Coding algorithms for defining comorbidities in ICD-9-CM and ICD-10 administrative data," Medical Care, vol. 43, no. 11, pp. 1130-1139, 2005. 
[18] J. F. Piccirillo, A. Vlahiotis, L. B. Barrett, K. L. Flood, E. L. Spitznagel, and E. W. Steyerberg, "The changing prevalence of comorbidity across the age spectrum," Critical Reviews in Oncology/Hematology, vol. 67, no. 2, pp. 124-132, 2008.

[19] M. Soares, J. I. F. Salluh, N. Spector, and J. R. Rocco, "Characteristics and outcomes of cancer patients requiring mechanical ventilatory support for $>24 \mathrm{hrs,"} \mathrm{Critical} \mathrm{Care} \mathrm{Medicine,} \mathrm{vol.} \mathrm{33,}$ no. 3, pp. 520-526, 2005.

[20] A. Freitas, T. Silva-Costa, F. Lopes et al., "Factors influencing hospital high length of stay outliers," BMC Health Services Research, vol. 12, no. 1, article 265, 2012.

[21] T. C. Collins, J. Daley, W. H. Henderson, and S. F. Khuri, "Risk factors for prolonged length of stay after major elective surgery," Annals of Surgery, vol. 230, no. 2, pp. 251-259, 1999.

[22] V. D. Rosenthal, S. Guzman, and P. W. Orellano, "Nosocomial infections in medical-surgical intensive care units in Argentina: attributable mortality and length of stay," The American Journal of Infection Control, vol. 31, no. 5, pp. 291-295, 2003.

[23] V. R. Dhamidharka, L. Y. Agodoa, and K. C. Abbott, "Effects of urinary tract infection on outcomes after renal transplantation in children," Clinical Journal of the American Society of Nephrology, vol. 2, no. 1, pp. 100-106, 2007.

[24] C. Y. Kang, O. O. Chaudhry, W. J. Halabi et al., "Risk factors for postoperative urinary tract infection and urinary retention in patients undergoing surgery for colorectal cancer," American Surgeon, vol. 78, no. 10, pp. 1100-1104, 2012.

[25] M. Medina, G. Martínez-Gallego, M. Sillero-Arenas, and M. Delgado-Rodríguez, "Risk factors and length of stay attributable to nosocomial urinary tract infection in general surgery patients," Enfermedades Infecciosas y Microbiologia Clinica, vol. 15, no. 6, pp. 310-314, 1997.

[26] C. D. Givens and R. P. Wenzel, "Catheter-associated urinary tract infections in surgical patients: a controlled study on the excess morbidity and costs," The Journal of Urology, vol. 124, no. 5, pp. 646-648, 1980.

[27] A. O. Ojo, J. A. Hanson, H.-U. Meier-Kriesche et al., "Survival in recipients of marginal cadaveric donor kidneys compared with other recipients and wait-listed transplant candidates," Journal of the American Society of Nephrology, vol. 12, no. 3, pp. 589-597, 2001.

[28] D. H. Lee, K. J. Buth, B.-J. Martin, A. M. Yip, and G. M. Hirsch, "Frail patients are at increased risk for mortality and prolonged institutional care after cardiac surgery," Circulation, vol. 121, no. 8, pp. 973-978, 2010.

[29] J. Afilalo, S. Mottillo, M. J. Eisenberg et al., "Addition of frailty and disability to cardiac surgery risk scores identifies elderly patients at high risk of mortality or major morbidity," Circulation: Cardiovascular Quality and Outcomes, vol. 5, no. 2, pp. 222-228, 2012.

[30] A. B. Massie, L. M. Kuricka, and D. L. Segev, "Big data in organ transplantation: registries and administrative claims," American Journal of Transplantation, vol. 14, no. 8, pp. 1723-1730, 2014. 


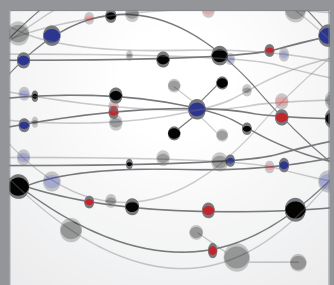

The Scientific World Journal
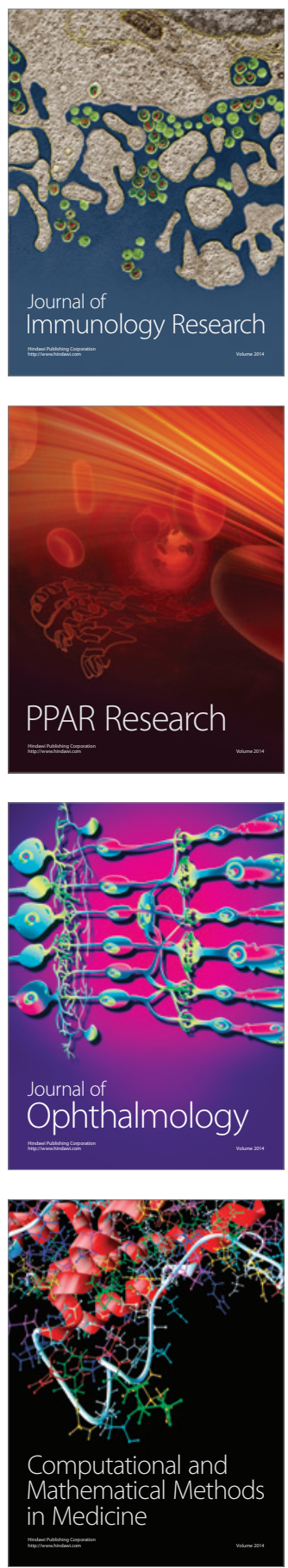

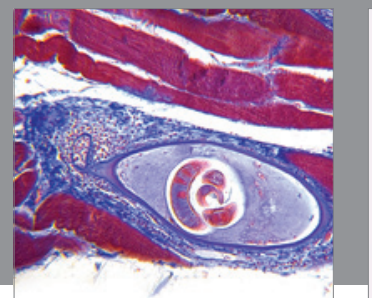

Gastroenterology

Research and Practice
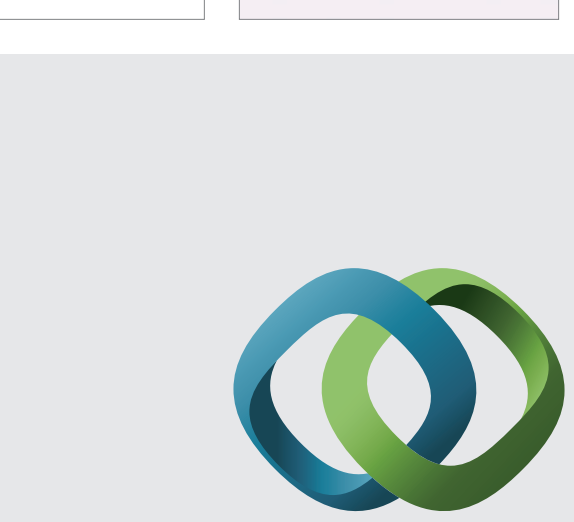

\section{Hindawi}

Submit your manuscripts at

http://www.hindawi.com
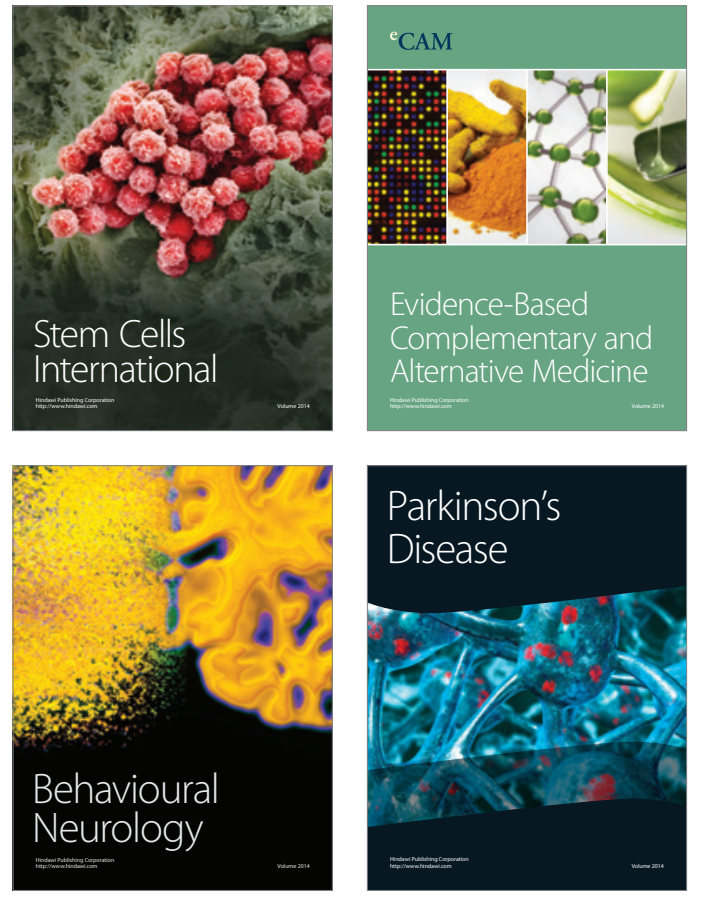
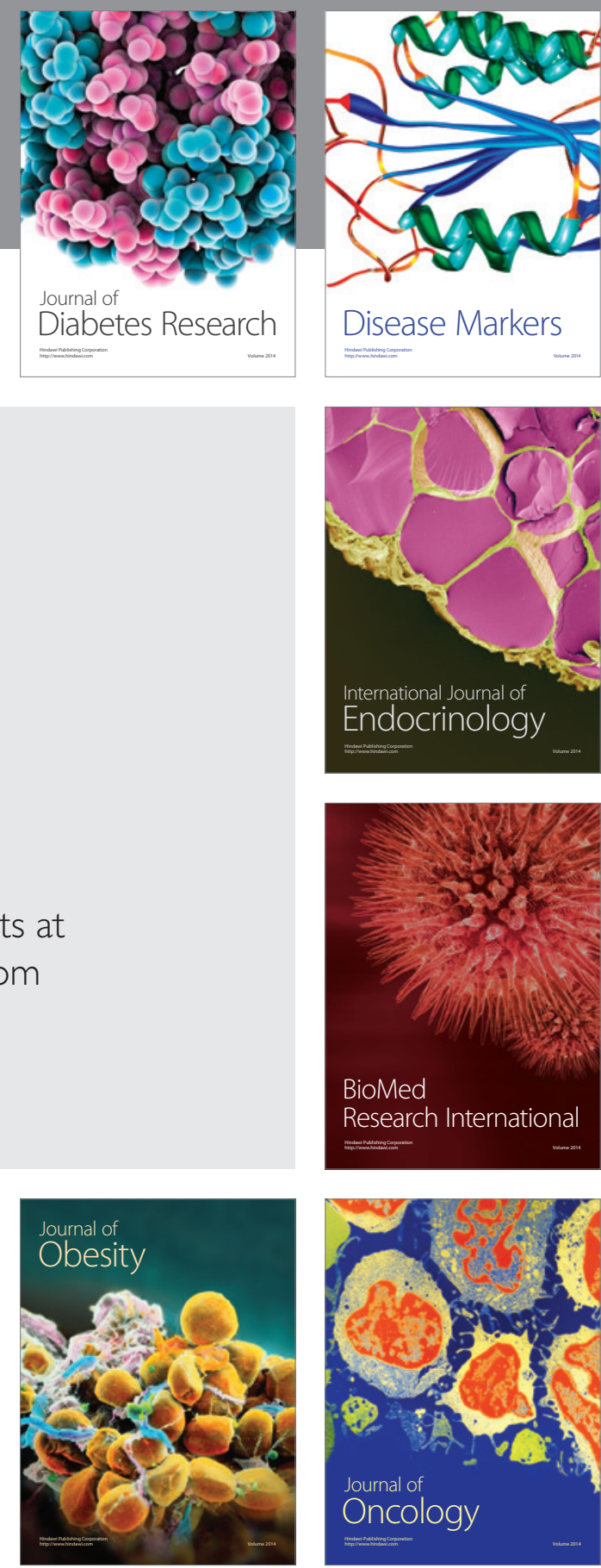

Disease Markers
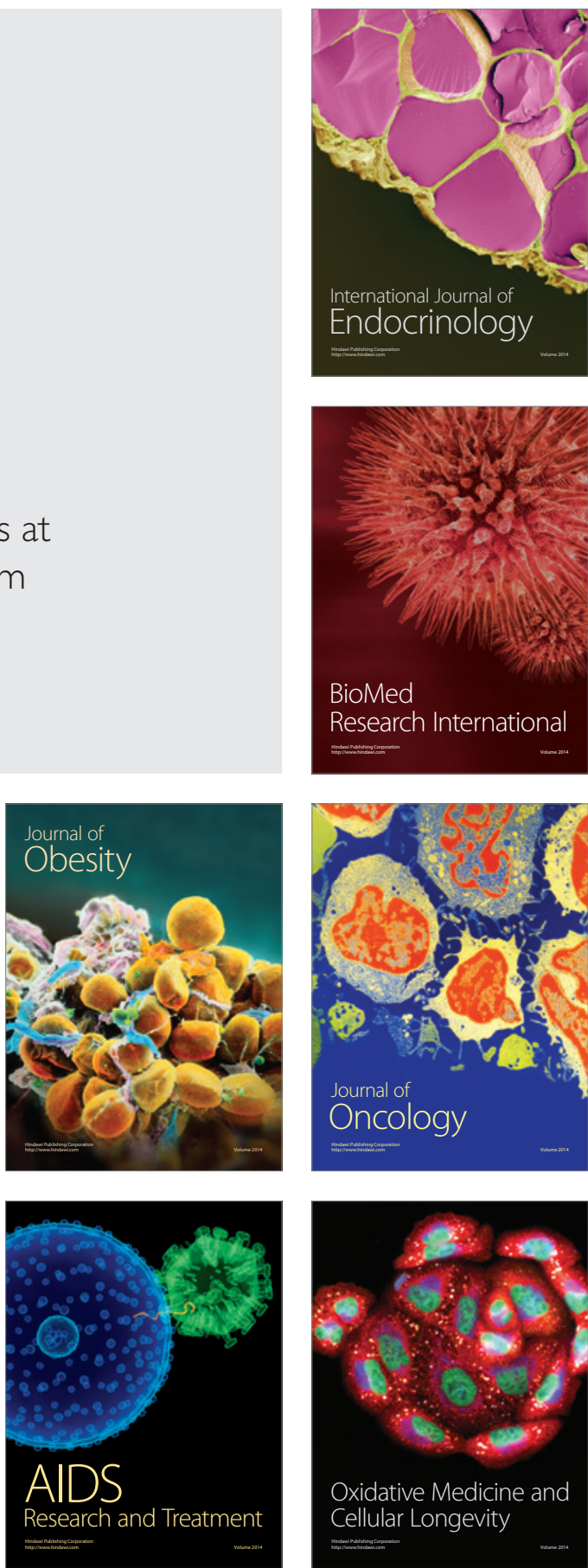